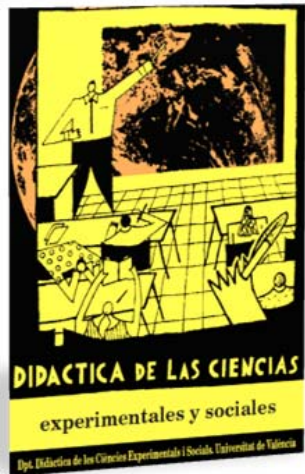

\title{
La memoria democrática en las aulas de secundaria y bachillerato: balance de una experiencia didáctica
}

\author{
Democratic memory in secondary school and \\ college: assessment of a didactic experience
}

DOI: $10.7203 / D C E S .34 .12048$

\author{
Vicent Galiana i Cano \\ Universidad de Santiago de Compostela \\ vicent.galiana.cano@gmail.com
}

\begin{abstract}
RESUMEN: Este artículo presenta los resultados de una investigación sobre la concepción y el conocimiento de la memoria democrática en las aulas de secundaria y bachillerato, mediante la confección e implementación de una propuesta didáctica sustentada sobre la historia local y la concepción del aula como un lugar de investigación. A su vez, se analizan los mecanismos de aprendizaje, las transformaciones de la percepción del alumnado y los resultados del proyecto didáctico, que permiten ofrecer, de este modo, algunas claves para el trabajo de la historia y la memoria en la enseñanza de la Guerra Civil y la represión franquista.
\end{abstract}

Palabras Clave: Memoria democrática, represión franquista, propuesta didáctica, enseñanza de la historia, investigación.

ABSTRACT: This article presents the results of an investigation on the conception and knowledge of democratic memory in secondary school and college. This study is accomplished by means of the preparation and implementation of a didactic proposal based on the local history and the conception of the classroom as a space for research. Likewise, learning mechanisms, transformations in the perception of the students and results of the didactic project are analysed, which permit us to provide, therefore, some keys for the work of history and memory in learning the Spanish Civil War and Francoist repression.

KEYwORDS: Democratic memory, Francoist repression, Didactic proposal, History Teaching, Investigation.

Fecha de recepción: febrero de 2018

Fecha de aceptación: junio de 2018

Vicent Galiana i Cano es doctorando en Historia Contemporánea en la Universidad de Santiago de Compostela y, temporalmente, investigador junior contratado por la Cátedra Interuniversitaria de Memoria Democrática de la Comunitat Valenciana en la Universitat d'Alacant. Ha sido promotor y codirector del proyecto educativo "La memòria democràtica com a ferramenta educativa del s. XXI”, financiado por la Conselleria de Justícia, Administració Pública, Reformes Democràtiques i Llibertats Públiques de la Generalitat Valenciana e implementado durante los meses de septiembre y octubre de 2017 en el IES Rodolfo Llopis de Callosa d'en Sarrià (Alicante). 


\section{INTRODUCCIÓN}

El presente trabajo presenta los resultados de la investigación realizada con el proyecto "La memòria democràtica com a ferramenta educativa del s. XXI", implementado durante los meses de septiembre y octubre de 2017 en el IES Rodolfo Llopis (Callosa d'en Sarrià) al conjunto del alumnado de ESO y Bachillerato, con un total de 18 grupos y cerca de 400 alumnos.

Su financiación fue aprobada en el DOGV del 9 de agosto de 2017 ( $\mathrm{n}^{\circ}$ 8102), referente a ayudas de la Direcció General de Reformes Democràtiques i Accés a la Justícia y la Conselleria de Justícia, Administració Pública, Reformes Democràtiques i Llibertats Públiques, en materia de recuperación de la memoria histórica con el fin de promover la convivencia democrática de la Comunitat Valenciana para el año 2017.

Callosa d'en Sarrià es un municipio de la Marina Baixa (Alicante) muy golpeado por las consecuencias de la Guerra Civil y la represión franquista: 78 víctimas mortales, decenas de personas exiliadas y una población golpeada por el trauma, la represión y el olvido (Galiana i Cano, 2017). Como en muchos otros municipios golpeados por la represión política y marcados por los pasados traumáticos, se ha vivido un proceso de imposición del silencio que ha sido naturalizado en las aulas.

Así pues, el proyecto pretende aproximar al alumnado a los sucesos de la Guerra Civil y la represión franquista de posguerra, apostando por la historia local y el trabajo con fuentes primarias. $\mathrm{Y}$, a su vez, promover el acercamiento a los aprendizajes, reflexiones y debates que nos deben permitir consolidar valores democráticos, de convivencia y respeto recíproco mediante la memoria histórica y democrática.

A su vez, el presente artículo lleva por objeto plasmar los resultados obtenidos de la investigación implementada y presentar un balance de los mismos, con el objetivo de valorar la propuesta didáctica inicial y analizar los aprendizajes del alumnado.

\section{APROXIMACIÓN AL MARCO TEÓRICO}

Comprender las memorias que constituyen nuestros relatos históricos como sociedad es un ejercicio de reflexión imprescindible para entender nuestra realidad actual: las identidades, las filiaciones, los traumas y los corpus simbólicos que estructuran nuestra vida en sociedad. A su vez, abordarlo desde una perspectiva local nos permite reconstruir recuerdos e historias ocultas, silenciadas por las narrativas hegemónicas al respecto.

Siguiendo a Montserrat Iniesta (2011) entendemos la memoria democrática como un patrimonio cultural intangible compuesto por historias, memorias, espacios, experiencias identificadas y pruebas de la voluntad de continuar con ímpetu disidente inspirado por valores democráticos. Esto es, un cúmulo de experiencias individuales y colectivas transcurridas en la lucha por conseguir un sistema democrático que se caracterice por la defensa de la libertad y de la justicia, de los valores republicanos y de los derechos humanos. Cobra así especial importancia la vinculación del estudio y el trabajo sobre la guerra civil y la represión franquista con el compromiso democrático y la concienciación para con los Derechos Humanos.

Partimos de la concepción de que la represión franquista tuvo un carácter genocida, que jugó un papel crucial en la evolución y configuración de la sociedad posterior. Mediante la eliminación sistemática de la disidencia perpetrada tras el golpe de 1936, se buscaba anular las demandas sociales transformadoras que estaban logrando importantes cotas de poder y apoyo social, que hacían peligrar la posición privilegiada de la oligarquía española. Así pues, la represión franquista, entendida como genocidio, tiene unos efectos en la memoria colectiva tanto sobre los propios fenómenos represivos como sobre la movilización política y social anterior y posterior (Míguez, 2014). 
En este sentido, es necesario situar la represión y la violencia como la columna vertebral del nuevo régimen (Gómez y Marco, 2012) y entender la eliminación y/o desactivación de la disidencia como uno de los pilares fundamentales de la edificación y solidez del nuevo orden (Nuñez-Díaz, 2001).

A su vez, concebimos la represión franquista como un proceso poliédrico en el que se combinan varios mecanismos de un mismo universo represivo. Esto es, se superponen (y no se excluyen) diferentes engranajes y tipologías represivas (Galiana i Cano, 2015). Desde este punto de vista, el proyecto pretende combinar el estudio y la comprensión de la tortura física y la eliminación de la disidencia con diversos métodos de represión social, económica y cultural.

Con este objetivo, las fuentes originales utilizadas responden a dos criterios fundamentales: por un lado, democratizar el impacto de la represión y superar la visión reduccionista del concepto "víctima”, reconociendo pero superando las víctimas mortales e integrando diferentes mecanismos represivos. Por otro lado, adaptándose al nivel para el que van dirigidos: eligiendo para cada curso documentos de dificultad y profundidad apropiada.

Además, el proyecto pretende vehicular la relación pasado-presente mediante el trabajo de campo, las salidas del aula, la puesta en valor del patrimonio memorial, cultural e arquitectónico y el uso de fuentes orales.

Explicaba Ronald Fraser en su ya clásico Recuérdalo tú y recuérdalo a otros. Historia oral de la Guerra Civil española (2001) que el uso de las fuentes orales nacía de un "intento de revelar el ambiente intangible de los sucesos, de descubrir el punto de vista y las motivaciones de los participantes”. Esta perspectiva cercana, social, construida sobre las fuentes orales juega un papel fundamental en nuestro proyecto: mediante la participación de personas que vivieron de un modo u otro los sucesos, a través de la visualización de videos y documentales y con la ayuda de los familiares en la investigación del alumnado.

En la investigación historiográfica existe un amplio consenso en torno al uso de las fuentes orales como herramienta de investigación en la Historia del Tiempo Presente. Unas fuentes que deben ser valoradas críticamente con el método científico pero que nos acercan a la problematización de la relación historia-memoria e integran, en las aulas, nuevas metodologías de aprendizaje que pueden ayudar a construir un mayor aprendizaje de la historia, con mayor interiorización del conocimiento y empatía e identificación del alumnado hacia los problemas históricos (Prades, 2016).

De hecho, en la última década hemos vivido un apasionante debate sobre la relación y complementación de la historia y la memoria: según Cuesta (2011a) se ha producido un reordenamiento de sus fronteras, hasta el punto que algunos historiadores han apostado por eliminarlas al interpretarlas como falsas delimitaciones innecesarias (Chartier, 2005).

El proyecto didáctico parte de la convicción de construir en la enseñanza secundaria una «historia con memoria» que se construya colectivamente y poniendo en valor las voces del pasado. Esto es, concebir, en palabras de Rüsen (2007), la historia como una forma elaborada de memoria.

Por otro lado, la Unidad Didáctica (UD) implementada se sustenta sobre el trabajo con fuentes primarias y la concepción del aula como lugar de investigación. Rehuyendo de ofrecer al alumnado unos contenidos cerrados de producción unidireccional que deban memorizar, se les guiará para que, junto a sus compañeros y desarrollando las competencias clave, elaboren ellos mismos el tema. Así, priorizando los contenidos procedimentales y estimulando el pensamiento crítico e histórico, será el propio alumnado quien elabore buena parte del contenido de la unidad (Grupo Ínsula Barataria, 1994).

Entendemos la historia como una construcción historiográfica, mediante la cual el alumnado se convierte en parte implicada en la construcción y el pensamiento histórico. Además, a través de este proceso de construcción, el alumnado desarrollará y ejercitará su capacidad crítica y analítica, lo que le permitirá comprender los contenidos con mecanismos más autónomos y personales y, a su vez, con mayor facilidad y profundidad. 
Así, la metodología implementada pretende eludir las dinámicas de explicación magistral que acostumbran a hegemonizar las clases de historia, para convertir el aula en un lugar de investigación (Montoya, 2008).

Situando la memoria como un elemento central del conocimiento del pasado reciente, el proyecto pretende combinar el trabajo sobre fuentes primarias y la elaboración de argumentarios por parte del alumnado con el fin de trabajar y dar a conocer las consecuencias de la Guerra Civil y la represión franquista de posguerra en un contexto cercano, superando el modelo de las Historias Generales (Maestro, 2002). Entendemos que priorizar el trabajo sobre la realidad local y establecer múltiples relaciones y conexiones con el presente, puede aumentar el nivel de comprensión e implicación del alumnado en el proceso de aprendizaje.

De acuerdo con los criterios fijados por la UNESCO, el presente proyecto integra las competencias para la vida como pilares fundamentales en su diseño, contenido y estructura: aprender a conocer, aprender a hacer, aprender a ser y aprender a convivir.

\section{LA MEMORIA DEMOCRÁTICA EN EL CURRÍCULUM, LOS MANUALES ESCOLARES Y LAS AULAS}

\subsection{La memoria democrática en el currículum}

Según el marco legal competente, la guerra civil -contenido curricular óptimo a partir del cual integrar la memoria democrática- se trabaja en $4^{\circ}$ de ESO y $2^{\circ}$ de Bachillerato. En el primero de los casos, figura en último lugar de un bloque histórico que incluye, entre otros, la economía del período de entreguerras, el estudio del fascismo y del nazismo, la evolución de la URSS o la II República. En Bachillerato, pese a mantener mayor centralidad y ser un contenido habitual en las pruebas PAU, el currículum dicta trabajar en las causas de la revuelta militar, las fases de la guerra, la evolución política y la represión en las retaguardias de ambos bandos, el contexto internacional o el desenlace del conflicto, así como sus consecuencias.

El proyecto parte de la concepción de que es necesario integrar e implementar la memoria democrática de manera transversal en la educación secundaria como herramienta implicada en el conocimiento del pasado, la creación de estudiantes críticos y la puesta en valor de los Derechos Humanos.

Una concepción parcialmente recogida en la Ley 14/2017, de 10 de noviembre, de la Generalitat, de memoria democrática y para la convivencia de la Comunitat Valenciana. En ella se establece en su artículo 33 que "la Conselleria competente en materia de educación incluirá la memoria democrática en el currículo de la educación primaria, de la educación secundaria obligatoria, del bachillerato [...] y promoverá las enseñanzas democráticas y de defensa de los derechos humanos contenidas en las gestas colectivas e individuales que las personas antifranquistas desempeñaron en su lucha contra la dictadura”.

A su vez, el DECRET 87/2015, de 5 de juny, del Consell, pel qual establix el currículum i desplega l'ordenació general de l'Educació Secundària Obligatòria i del Batxillerat a la Comunitat Valenciana, vinculado al desarrollo autonómico del Real Decreto 1105/2014, de 26 de diciembre, establece como competencia clave la competencia social y cívica.

Así pues, pese a la inexistencia explícita directa de la memoria democrática y los valores éticos y cívicos vinculados al conocimiento y fomento de los Derechos Humanos en alguno de los cursos de ESO y Bachillerato, entendemos que el marco legislativo reconoce la posibilidad y la idoneidad de trabajar la memoria democrática de manera transversal. 


\subsection{La memoria democrática en los libros de texto}

Cuantitativamente, la memoria democrática ocupa un espacio reducido en los niveles educativos referidos. Si bien su centralidad en el currículum de ESO y Bachillerato se ha visto incrementada a raíz de los cambios legislativos de 2007 en el conjunto del estado, para algunos autores la presencia de la memoria histórica en los libros de textos escolares es, todavía hoy, insuficiente (Díez Gutiérrez, 2014).

Pero, más allá de su presencia, es necesario visualizar su contenido. Los manuales escolares de secundaria tienden a vincular la Guerra Civil a la II República, insertándolas en un mismo epígrafe (Bel y Colomer, 2017). A su vez, destacan el período de reformas republicanas haciendo especial énfasis en las respuestas sociales que generaron y en la movilización de los sectores conservadores. Entendemos que este hecho puede ayudar a dibujar al alumnado posibles relaciones de causalidad entre el gobierno democrático y el alzamiento militar y oligárquico. La imagen que se transmite en los manuales escolares alimenta con especial énfasis dos de las memorias emblemáticas existentes: en primer lugar, el relato ofrecido por la historiografía franquista del 18 de julio de 1936 como respuesta a la situación existente; y en segundo lugar, el relato ahistórico y apolítico que concibe la Guerra Civil como una tragedia fratricida, un error colectivo en el que todos los agentes inmersos eran, en mayor o en menor medida, responsables y que, a su vez, cabe superar y olvidar.

Un relato parcial que, a su vez, acarrea notables problemas con la conceptualización de la propia dictadura franquista, aislándola de las corrientes fascistas y definiéndola como «dictadura», «régimen dictatorial», «régimen autoritario» o «tradicionalismo español» que, más allá de vagas referencias, no son definidos ni explicados con profundidad (Fuertes, 2018).

\subsection{La memoria democrática en las aulas}

Pese a ello, si sigue vinculando en el estudio y el aprendizaje en las aulas de la Guerra Civil con la idea de «conflicto» y poniendo en boga las dificultades de enseñar-aprender sobre problemas históricos no asentados sobre consensos sociales (Molpeceres, 2011; Cortés, 2014).

Como explica Rafael Vall (2007), en diversos proyectos didácticos el alumnado ha mostrado sus deseos de aprender con una historia más vinculada a la vida, más útil y práctica, de la que se pueden extraer aprendizajes de los errores del pasado. Una historia, en definitiva, que debe partir de los espacios y pasados cercanos mediante los cuales el alumnado pueda aprender y debatir de manera razonada y contrastada, estimulando la reflexión, el trabajo con fuentes primarias y la autonomía del alumnado.

\section{EL PROYECTO DIDÁCTICO}

\subsection{IES Rodolf Llopis: una aproximación al centro y su alumnado}

El presente proyecto se ha desarrollado durante los meses de septiembre y octubre de 2017 en el IES Rodolf Llopis de Callosa d'en Sarrià. Éste municipio de la Marina Baixa cuenta con 7.223 habitantes, de los que 1260 son personas migrantes - un 47\% procedentes de Ecuador y un 13\% de Bolivia, siendo éstas las dos comunidades nacionales con mayor población el municipio-. El crecimiento de su población ha estado vinculado en las últimas décadas a la efervescencia del sector terciario en la zona - que cuenta con enclaves turísticos como Benidorm, Altea o Calp- y a la consolidación de la economía agraria, tanto local como comarcal.

Su localización en una zona de afluencia migratoria, permite que el centro cuente con una gran diversidad étnica y cultural. Y, a su vez, unas historias familiares divergentes: los ascendientes 
de prácticamente la mitad del alumnado - cerca del 48\%- no vivían en este territorio durante el período estudiado.

En el proyecto han participado 468 escolares entre los distintos de ESO y Bachillerato (Tabla 1). Entre el alumnado, encontramos un $53 \%$ de mujeres frente a un $47 \%$ de hombres en los cursos de ESO, mientras que en bachillerato estas cifran se transforman ligeramente: un $60 \%$ de mujeres frente a un $40 \%$ de hombres. En aquello referente al origen geográfico, el alumnado procedente de otros países representa el $45 \%$ en ESO y el 25\% en Bachillerato, procedentes principalmente de Ecuador, Bolivia, Argentina, Rumania y Marruecos, por este orden de importancia.

Durante el diseño y la implementación de la UD se han tenido en cuenta los factores socioeconómicos del alumnado y se han confeccionado las actividades con el objetivo de que todo el alumnado pueda contribuir y trabajar de igual manera independientemente de su pasado familiar.

TABLA 1. Alumnado por curso

\begin{tabular}{cc}
\hline $1^{\text {o }}$ de ESO & 110 \\
\hline $2^{\text {o }}$ de ESO & 96 \\
\hline $3^{\text {o }}$ de ESO & 85 \\
\hline $4^{\text {o de ESO }}$ & 72 \\
\hline $1^{\text {o de Bachillerato }}$ & 45 \\
\hline $2^{\text {o }}$ de Bachillerato & 42 (Humanístico) \\
& 18 (Científico) \\
\hline TOTAL & 468 \\
\hline
\end{tabular}

Fuente: IES Rodolf Llopis. Elaboración propia.

\subsection{Calendario de implementación del proyecto}

La UD se ha implementado entre el 27 de septiembre y el 20 de octubre de manera consecutiva en las clases de Geografía e Historia (ESO), Geografía e Historia, Historia del Mundo Contemporáneo ( $1^{\circ}$ de bachillerato) e Historia de España $\left(2^{\circ} \text { de Bachillerato }\right)^{1}$. Así, pese a que no todos los cursos y grupos iniciaron del trabajo el mismo día, en todos los casos las sesiones fueron consecutivas y en el menor espacio temporal posible. De igual manera, cabe destacar que el 13 de octubre todo el alumnado había finalizado las sesiones en el aula y hasta el día 20 se realizaron las actividades complementarias.

\subsection{Diseño del proyecto}

La UD mantiene una estructura compartida para la totalidad de los cursos para los que fue diseñada. Entendemos que en ningún caso el mantenimiento de una estructura compartida dificulta la implementación del proyecto, dado que se ha prestado enorme atención a la adaptación de los contenidos y las dinámicas a los distintos niveles educativos.

La UD se estructura en tres bloques y ha sido diseñada para su desarrollo en 5 sesiones, adaptándose a los requisitos establecidos tanto por la entidad financiadora como por los acuerdos alcanzados con la dirección del centro (Tabla 2).

Desde otro prisma, las actividades y la evaluación han estado diseñadas con el objetivo de desarrollar las Competencias Clave. Creemos fundamental destacar los esfuerzos realizados tanto

\footnotetext{
${ }^{1}$ En contadas ocasiones la UD se ha implementado en el horario de Educación Física o Tutorías por incompatibilidad de horarios.
} 
en la panificación como en la ejecución del proyecto para implementar, en primer término, la Competencia Aprender a Aprender (CAA) mediante el uso de fuentes primarias y la autonomía del alumnado en la construcción de explicaciones históricas, base fundamental del proyecto. En segundo término, la Competencia Comunicación Lingüística (CCLI) tanto en la puesta en valor de vocabulario específico de la UD como en la centralidad de los debates, redacciones, formulación de respuestas y argumentaciones por parte del alumnado. En tercer lugar, la integración del alumnado en conceptos, marcos y valores como los que acompañan el trabajo sobre la democracia, los derechos humanos, la memoria, la violencia política o las dictaduras, nos permite abordar en el aula la Competencia social y cívica (CSC), necesario para la educación de ciudadanos críticos, responsables y con valores y compromiso democrático, ético e igualitario. Por último, es esencial para el presente proyecto el trabajo con imágenes y fotografías, así como el visionado y análisis de recursos audiovisuales, trabajando en la concienciación y la expresión cultural (CEC).

TABLA 2. Estructura del proyecto

\begin{tabular}{|c|c|c|}
\hline Bloque & Sesión & Contenido \\
\hline \multirow{4}{*}{$\begin{array}{l}\text { Planteamiento del problema y } \\
\text { provocación de interrogantes }\end{array}$} & Sesión 1 & Conocimientos previos \\
\hline & & Explicación del procedimiento \\
\hline & & Trabajo sobre fuentes gráficas \\
\hline & & Problematización \\
\hline \multirow[t]{2}{*}{ El proyecto de investigación } & Sesión 2 & Trabajo sobre fuentes primarias \\
\hline & Sesión 3 & Exposición de resultados \\
\hline \multirow[t]{6}{*}{ Cierre y resultados } & Sesión 4 & Valoración colectiva \\
\hline & & Conclusiones \\
\hline & & Educación y género \\
\hline & Sesión 6: actividad & Visita a los espacios de la \\
\hline & complementaria & memoria: fomento de la \\
\hline & & relación pasado-presente \\
\hline
\end{tabular}

Fuente: Elaboración propia

Con todo, la periodización, el contenido y las dinámicas de las sesiones son los siguientes:

- Sesión 1: Introducción

Centrada en aproximar al alumnado a la Declaración Universal de Derechos Humanos, el trabajo sobre sus conocimientos y concepciones previas de la Guerra Civil y el franquismo y la aproximación al marco contextual, con especial énfasis en la realidad valenciana y la vida cotidiana en el marco local. En esta primera sesión juega un papel fundamental el uso de fotografías, la visualización de vídeos breves y la participación activa del alumnado en debates, con "lluvia de ideas” y dinámicas de grupo. Esto nos permite problematizar el contenido, acercar al alumnado a la problemática y conocer sus conocimientos y creencias previas. A su vez, sus intervenciones y respuestas serán claves para poder dibujar una imagen inicial de concepciones e informaciones previas con dos objetivos distintos: por un lado, adaptar y acercar los contenidos y los procedimientos a sus conocimientos y concepciones iniciales, con el objetivo de optimizar el trabajo, facilitar el aprendizaje y estimular el interés. Por otro lado, para poder valorar el impacto global del proyecto. 
- Sesión 2: Trabajo con fuentes primarias

Centrada en el trabajo sobre fuentes primarias de la represión franquista en el ámbito local. Se les facilita al alumnado tanto una copia de los documentos originales como, posteriormente, el texto transcrito para facilitar la lectura. El alumnado trabaja las fuentes primarias, por parejas o grupos reducidos (4-5 personas), para extraer su autoría, contexto y contenido y reflexionar con la pareja o el grupo en torno a ellas.

\section{Los documentos utilizados}

1 de ESO: Documentos del Registro Civil de Callosa d'en Sarrià referentes al cambio de nombre de personas motivado por la Orden de 9 de febrero de 1939 para imposición de nombres a los inscritos que tuvieran exóticos o extravagantes. En concreto, las actas de nacimiento y los documentos referidos al cambio de nombre de Líria Roig Sellés ${ }^{2}$ y Placer Mollà Galiana ${ }^{3}$.

$2^{\circ}$ de ESO: Extractos del libro de actas del Ayuntamiento de 1939 y 1940 referidos al cambio de nomenclatura de espacios públicos. En concreto, las referentes a la instauración de la Avenida del Generalísimo, la calle José Calvo Sotelo, la Calle del General Mola y la calle José Antonio Primo de Rivera.

$2^{\circ}$ Ciclo de ESO: Documentación del Archivo Municipal referida, por un lado, a los expedientes de depuración de funcionarios municipales a raíz de la Ley de Responsabilidades Políticas y, por otro lado, el Acta del Ayuntamiento de la sesión extraordinaria del 7 de octubre de 1939.

En el primero de los casos, se trabaja sobre los expedientes de depuración de Cayetano Pastor Ivorra, vigilante nocturno, y José Mayor Guardiola, guardia municipal. En ambos casos, los investigados mantienen sus puestos de trabajos después de pronunciarse afectos al "glorioso movimiento nacional”.

En el segundo, el acta del 7 de octubre de 1939 corresponde a la aprobación de la concesión del título de Alcaldesa Honoraria a la Virgen de las Injurias, hasta ese momento considerada la patrona del pueblo, “por la gracia del Caudillo” y al grito de “Arriba España”. Además, en el acta se manifiesta una exaltación de la idea de Guerra Civil como cruzada cristiana.

Bachillerato: Fragmentos del Procedimiento Sumarísimo de Urgencia $n^{0}$ 5045, iniciado el 20 de abril de 1939 contra Javier Tasa Sanchis -vecino de Callosa y militante del PCE- que finalmente fue condenado a pena de muerte por el delito de “agresión a la rebelión con agravantes” y fusilado en el Cementerio de Alicante el 10 de julio de $1941^{4}$.

- Sesión 3: Trabajo con fuentes primarias (II)

En la tercera sesión el alumnado expone los resultados del análisis de las fuentes, complementa la información que contenía la documentación y se crean de manera cooperativa cuadros-resúmenes de las conclusiones generales de cada grupo y del conjunto de la clase.

En aquello referente a la complementación y ampliación de información, se le encarga, al final de la Sesión 2, al alumnado distintos trabajos a realizar fuera del horario de clase. Por situar algunos ejemplos: al alumnado de 2 de ESO, se le encarga la investigación sobre quiénes eran las personas que recibían calles en su honor y al alumnado de Bachillerato, la realización de pequeñas entrevistas a gente mayor de su familia o vecindario en torno a sus recuerdos y los de sus familiares en la Guerra Civil.

\footnotetext{
${ }^{2}$ Hija de Dionisio Roig Palacio - militante de la UGT, condenado a pena de muerte en rebeldía y en huido al exilio- y Rosa Roig Palacio, y nacida el veinte de diciembre de 1937, obligada a cambiar su nombre el 20 de junio de 1939 por el de Rosa.

${ }^{3}$ Hija de José Mollà Ronda -militante de la CNT exiliado a Francia- y María Galiana Mollar, quien acudió al Registro Civil el 24 de junio de 1939 para modificar el nombre de su hijo, Placer Mollà Galiana, por el de José.

${ }^{4}$ Una historia de vida de Javier Tasa Sanchis y un análisis de su procedimiento judicial se puede encontrar en Galiana i Cano (2015).
} 
- Sesión 4: Conclusiones

La cuarta sesión se dedica, por un lado, a la elaboración de las conclusiones y la valoración del proyecto por parte del alumnado. Y, por otro lado, a la visualización y debate de contenidos referidos a la educación de las mujeres durante el franquismo. De acuerdo con el Plan integral contra la violencia de género que viene desarrollando el centro en los últimos cursos, se trabajó y se debatió sobre el manual escolar Cómo se educó Carmina de Federico Torres publicado de 1950, particularmente sobre el capítulo XVIII de dicho manual que lleva por título "Labores femeninas", y fragmentos del manual Economía doméstica para bachillerato y magisterio, publicado por la Sección Femenina de la Falange Española en 1958.

\section{- Actividad Complementaria}

Una vez terminadas las sesiones en el aula, la totalidad del alumnado realiza actividades complementarias, en su mayoría salidas del centro financiadas por la Conselleria de Justícia, Administració Pública, Reformes Democràtiques i Llibertats Públiques y totalmente gratuitas para el alumnado, encaminadas a fortalecer la comprensión de las relaciones pasado-presente y conocer el patrimonio arquitectónico, cultural y social de nuestro entorno.

\section{1r Ciclo de ESO:}

Visita al Espai per la Memòria en el cementerio de Callosa d'en Sarrià. Un monolito con el nombre de las 78 víctimas mortales del municipio que pudieron visitar acompañados por miembros del Col-lectiu per la Recuperació de la Memòria Històrica de Callosa d'en Sarrià y escuchar y dialogar con Blanca Berenguer, hija de Jaume Berenguer Peres, militante republicano abatido el 20 de julio de 1938 en Alcublas (Serrans, València) sobre el proceso de pérdida de su padre, su lucha por la memoria y la importancia de la construcción del monolito. Después pudieron conversar con ella, que respondió a las dudas que le plantearon.

\section{$\underline{2^{\circ} \text { de ESO: }}$}

Presentación y visualización del documental Fills del silenci, producido por la Diputació de València y dirigido por Rosa Brines. El documental, orientado al alumnado de secundaria, explica la lucha de los descendientes de las personas represaliadas por recuperar su memoria y sus vivencias. Se organizó un debate posterior en el que el alumnado pudo explicar y confrontar sus conclusiones así como conversar y preguntar a representantes de la Delegación de Memòria Històrica de la Diputació de València que los acompañaron.

\section{$\underline{2^{\circ} \text { de ESO: }}$}

Visita al Refugio Cervantes - refugio antiaéreo construido por la Junta de Defensa Pasiva junto al Insituto Cervantes- y al Hospital Sueco-Noruego -Institución hospitalaria fundada en 1937que dio lugar al Hospital Militar gracias a la solidaridad de los países escandinavos y gracias a la acción de los Comités en Defensa de España- de Alcoi, acompañados por el historiador local Angel Beneyto.

\section{Bachillerato:}

Visita a València para realizar la ruta guiada "València capital de la República", centrada en la memoria urbana de la ciudad en los años 30, y poder visitar el refugio antiaéreo situado en el Ayuntamiento de la ciudad, guiados por profesores de Historia de la Universitat de València. 


\section{EVALUACión}

La evaluación del proceso de aprendizaje del alumnado se ha valorado desde tres prismas distintos: su implicación en el proyecto, los cambios en su percepción sobre la Guerra Civil y la represión franquista y asimilación de la información, y su capacidad de reflexión en el trabajo final.

\subsection{La implicación del alumnado en el proyecto}

En el primero de los casos, el alumnado ha mantenido un nivel de implicación y participación elevado, interviniendo en los debates, planteando preguntas y dudas y compartiendo las reflexiones que les sugerían las dinámicas de las sesiones. Si bien la implicación, en cantidad y calidad, se ha visto vinculada al nivel de estudios, el nivel de aceptación y colaboración del alumnado del 1r ciclo de ESO ha sido mayor del esperado. De igual manera, la asistencia a las actividades complementarias superó el 90\% en todos los cursos, llegando al 100\% en algunos de ellos.

Esta implicación se ha transformado progresivamente hasta alcanzar su nivel más alto en las últimas sesiones. A medida que se avanzaba hacia el plano cercano y local, el interés del alumnado crecía exponencialmente, construyendo espacios de discusión y aportando información recibida en los ambientes familiares. Del mismo modo, como veremos más adelante, la implicación de las familias ha enriquecido notablemente el aprendizaje y ha sido clave para la transformación de la percepción del alumnado.

\subsection{Cambios y continuidades en la percepción sobre la Guerra Civil y la represión franquista}

En aquello referente a los cambios en su percepción, el resultado confirma las potencialidades del proyecto y su idoneidad. Tanto en la "lluvia de ideas" inicial como en las primeras cuestiones planteadas al alumnado, a la pregunta «¿Cómo crees que se vivió la Guerra Civil y el primer franquismo en Callosa d'en Sarrià?» el contenido de las respuestas libres del alumnado se englobaron en las cuatro visiones recogidas en el Gráfico $1^{5}$.

GRÁFICo 1. Concepción previa: La Guerra Civil en Callosa d'en Sarrià
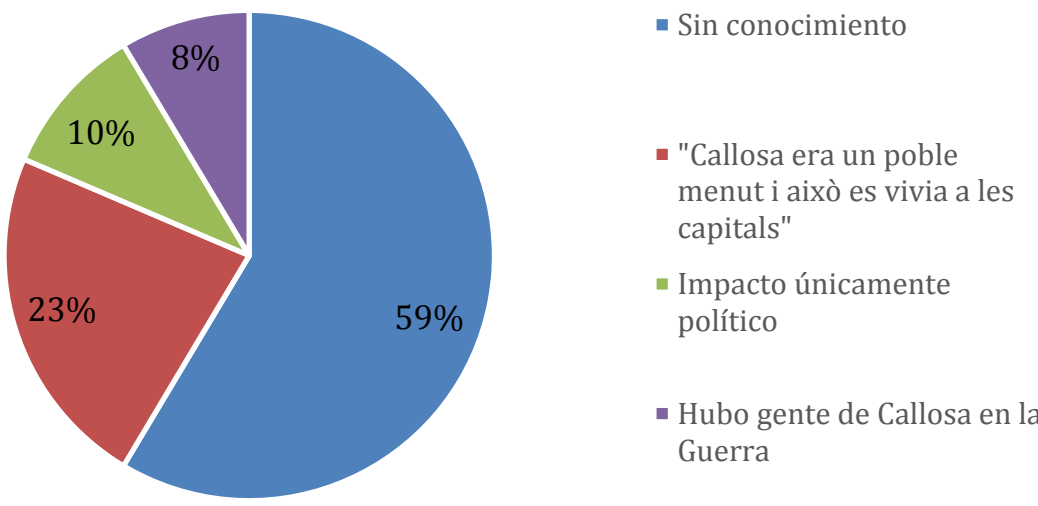

Fuente: Elaboración propia

\footnotetext{
${ }^{5}$ Las respuestas que aparecen en el gráfico agrupan la idea central de cada una de las respuestas en torno a 4 ejes que, en su interior, pueden mantener diferencias. Por ejemplo, "Callosa era un poble menut i això es vivia a les capitals" aglutina las respuestas que vinculan la inexistencia (o escasez) de consecuencias y de impacto al tamaño y el número de población del municipio. El gráfico muestra con proporcionalidad el peso de cada una de las respuestas. Tanto en la "lluvia de ideas" como en las primeras cuestiones, fueron planteadas y respuestas oralmente durante la primera sesión.
} 
Esta impresión previa, en cambio, mantiene notables diferencias en función de la edad del alumnado: los alumnos de Bachillerato mantienen una percepción centrada fundamentalmente en el impacto político y en la participación de vecinos del municipio, mientras que en el 1r ciclo de ESO las respuestas giran, de manera casi unánime, en torno al desconocimiento completo.

Desde otro punto de vista, en los escasos alumnos de primeros cursos de ESO que construían respuestas diferenciadas y argumentaban la importancia del impacto de la Guerra Civil y la represión franquista en el municipio, lo hacían por aprendizajes extraacadémicos, fundamentalmente por su historia familiar.

Durante la sesión de conclusiones, los comentarios del alumnado, así como sus respuestas a la misma pregunta, se centraron en lecturas muy distintas. Ante la repetición de la pregunta original, “¿Cómo crees que se vivió la Guerra Civil y el primer franquismo en Callosa d’en Sarrià?, las respuestas fueron sustancialmente distintas (Gráfico 2).

GRÁFICO 2. Percepción final: La Guerra Civil en Callosa d'en Sarrià

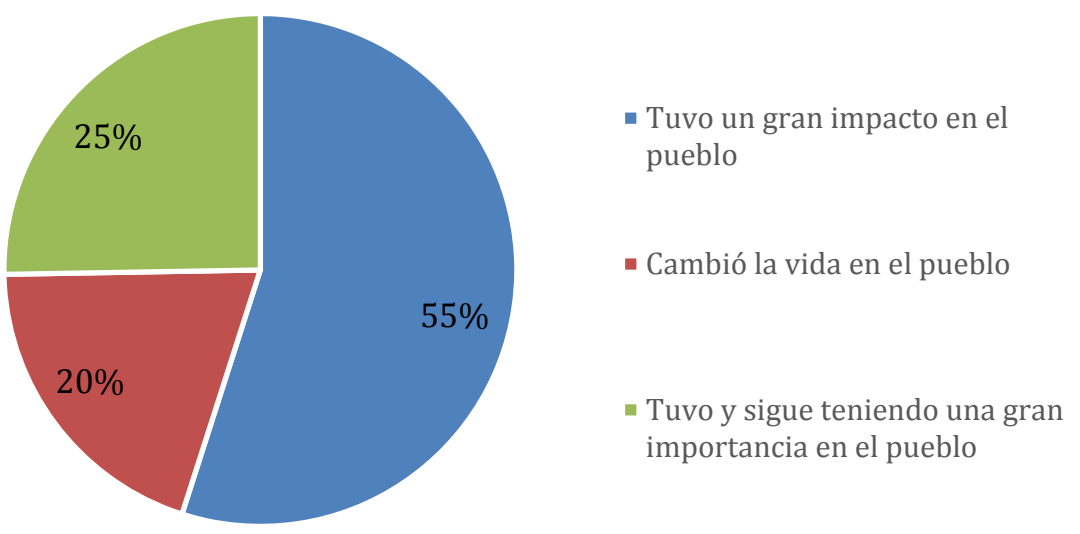

Fuente: Elaboración propia

Por último, en aquello referente al trabajo final, el alumnado ha entregado una redacción/ensayo con sus impresiones y aprendizajes del proyecto, con una estructura libre y diseñada con un objetivo doble: conocer su valoración y evaluar la recepción de nuestro trabajo. Para ello, se les facilitó distintas preguntas a las que debían responder o hacer referencia a lo largo del texto: ¿Qué opinión tienes de los talleres impartidos? ¿Ha sido de utilidad? ¿Conocías esta parte de la historia de Callosa? ¿Qué actividad te ha gustado más? ¿Qué es aquello que más te ha sorprendido? ¿Qué has aprendido durante este proyecto? ¿Cómo crees que se vivió la Guerra Civil y el primer franquismo en Callosa? Su contenido se analiza en el siguiente epígrafe.

\subsection{Análisis de las redacciones finales}

La información obtenida con la lectura y revisión de las diferentes redacciones entregadas nos ofrece una valiosa información sobre lo que ha supuesto este proyecto para el alumnado. De entre toda la información destacaremos los aspectos compartidos por la mayor parte de las redacciones ${ }^{6}$.

La mayoría del alumnado ha generado gran interés por las temáticas trabajadas y ha mostrado implicación, dado que muchos coinciden en que desconocen el período histórico al que nos hemos referido (II República, Guerra Civil, posguerra y Dictadura franquista) por no haberlos visto nunca a clase -se debe tener en cuenta que estos periodos tan sólo llegan a estudiar en $4^{\circ}$ de $\mathrm{ESO}$ y $2^{\circ}$ de Bachillerato- y no conocer su implicación en su realidad cercana.

\footnotetext{
${ }^{6}$ La pregunta “¿Cómo crees que se vivió la Guerra Civil y el primer franquismo en Callosa?” formaba parte de las cuestiones planteadas para realizar la redacción final y su el alumnado la respondió de forma individual en la misma.
} 
El alumnado del primer ciclo de ESO coincide en la dificultad de las primeras clases, la cantidad de conceptos nuevos que se introducían continuamente y la corta duración del proyecto. En cuanto a las fuentes primarias, destacan su primera “investigación” histórica y valoran positivamente la experiencia. Pese a ello su evaluación del proyecto es positiva y muestran predisposición a repetirlo.

En el caso del alumnado de $2^{\circ}$ de ESO valora de manera muy satisfactoria su actividad complementaria (la visita al cementerio de Callosa d'en Sarrià) y coinciden en el impacto que les produjo escuchar de personas que vivieron en primera persona el contexto histórico trabajado, sus experiencias y recuerdos.

El alumnado de $3^{\circ}$ de ESO, en cambio, ha valorado los talleres de forma diferente. Ha mostrado su interés en la temática, pero han coincidido en remarcar la mayor dificultad de trabajo de las fuentes primarias seleccionadas. En su caso, y ante el interés mostrado en la sesión inicial en lo referente a los bombardeos sobre territorio valenciano, se elaboró una presentación de imágenes diferenciada para la sesión de cierre, centrada en el impacto de los bombardeos y el papel de la aviación italiana.

El alumnado del último curso de ESO y los dos Bachilleratos comparte una valoración conjunta del proyecto. En ella, destaca tres elementos centrales: en primer lugar, la profundidad de las reflexiones y la valoración positiva del trabajo con fuentes primarias; en segundo lugar, se ha valorado de forma muy positiva las salidas realizadas en Alcoi y València, dotándolas de gran importancia en la redacción final; por último, en tercer lugar, se ha manifestado su deseo de repetir este tipo de talleres de temática similar, pero con mayor número de sesiones y una mayor profundidad.

Cabe destacar, de igual manera, que tanto el alumnado de $4^{\circ}$ de ESO como de $2^{\circ}$ de Bachillerato estudiarán los período histórico de la II República, la Guerra Civil y el Franquismo durante el tercer trimestre y, con este proyecto, han introducido desde una metodología didáctica diferenciada buena parte de los conceptos que estudiaran en los próximos meses.

Con todo, desde un prisma general, la mayor parte del alumnado afirma que desconocía el impacto de la Guerra Civil y la represión franquista en Callosa. Y, en consecuencia, en los textos finales se aprecia su sorpresa con los efectos que generaron la población local. De igual manera, la valoración de las actividades complementarias es muy positiva y ocupa un lugar predominante en sus redacciones finales.

Por último, nos parecen de gran interés las respuestas ofrecidas a la pregunta “¿Qué es aquello que más te ha sorprendido?” (Gráfico 3).

GRÁFICO 3. ¿Qué es aquello que más te ha sorprendido?

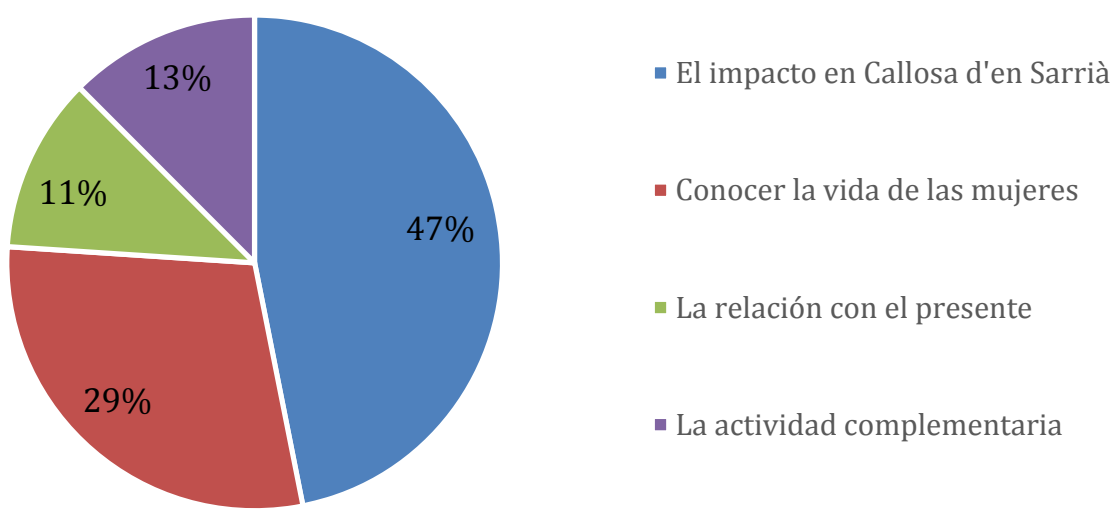

Fuente: Elaboración propia 
A su vez, y más allá de las valoraciones globales, reproducimos fragmentos de algunas redacciones para poder ilustrar la concepción y valoración del alumnado ${ }^{7}$.

Rodrigo, de $3^{\circ}$ de ESO, escribe: “el taller me ha gustado y es importante hacerlo porque ahora somos un poco más conscientes de lo que pasó, de la injusticia que se vivió y de lo que sufrió la gente. Y para mí, lo más importante, que nos hemos hecho una opinión y hemos podido debatir y conocer las opiniones de los demás en clase”. En este mismo sentido, Natalia, de $1^{\circ}$ de Bachillerato, argumenta que "no ha sido algo que hayamos tenido que estudiar para un examen, sino que hemos aprendido cómo las consecuencias de la Guerra Civil han estado muy cerca de nosotros, hemos empatizado con la gente que las sufrió. Ahora somos conscientes de lo que se vivió en el pueblo”.

La capacidad de generar empatía y el trabajo sobre la historia local y cercana también aparece destacada en diversos trabajos. Francisco, de $2^{\circ}$ de Bachillerato, nos explica que "personalmente me gusta la historia pero siempre nos explican la historia de otros sitios, las cosas que nos pillan lejos. Y nosotros no conocemos esas cosas. Por eso nos cuesta más de entender. Pero ahora hemos aprendido lo que sucedió aquí mismo, como afectó en nuestro pueblo, a nuestros antepasados. Es algo más próximo, más real. Ha estado muy bien”.

Por su parte María, de $1^{\circ}$ de ESO, resalta que "no era consciente de cómo vivían y eran tratadas las mujeres hace unos pocos años. Ahora puedo entender cómo piensa mi abuela”. Y, en esta misma línea, Carla, de $4^{\circ}$ de ESO, se pregunta “¿cómo es posible que mi madre o mis abuelas no me hayan hablado de cómo se educaron y vivieron ellas de jóvenes? A nosotras aún nos queda mucho por hacer, pero estudiando cuál era la situación y la educación de la mujer en la posguerra, hemos avanzado mucho".

Por último, las palabras de Fernando, de $4^{\circ}$ de ESO, nos pueden servir para ilustrar, de alguna manera, la valoración final del alumnado: "siempre estudiamos cosas que pasaron hace mucho tiempo y muy lejos de aquí. Pero ahora hemos aprendido qué pasó en nuestro entorno, con nuestros abuelos, y lo hemos estudiado mientras estudiábamos qué pasaba a nivel general. Hemos entendido cómo afectan las cosas generales en nuestro entorno. Eso me ha gustado. Y también poder debatirlo en clase, siendo nosotros los que explicábamos qué pasaba y conociendo qué es lo que creían otros, porque algunas veces entendíamos cosas distintas de un mismo documento”.

\section{ANÁlisis de RESUltados}

La valoración de la implementación de este proyecto, en tanto que director del mismo, y de acuerdo con las valoraciones obtenidas del alumnado, mediante las redacciones finales, es muy positiva.

En primer lugar, la buena acogida del proyecto y la voluntad del alumnado de sumarse a las actividades propuestas, mostrando un enorme deseo en aprender y reflexionar en torno a las experiencias históricas comprendidas en el periodo estipulado. Es por ello que creemos que este proyecto representa el inicio de un largo camino de trabajo, concienciación y reflexión colectiva que nos permita seguir educando en la memoria democrática.

En segundo lugar, nos reafirmamos en nuestra convicción inicial: la memoria democrática y la educación en valores y respeto a los Derechos Humanos es necesaria en todos los ámbitos educativos. Hemos constatado el gran desconocimiento por parte del alumnado y las potencialidades de poderlo trabajar en clase. Las redacciones de cierre muestran el interés generado, los aprendizajes compartidos y el afán del alumnado de seguir aprendiendo y reflexionar en torno al pasado de nuestro pueblo y nuestro país.

Desde un prisma general, entendemos que, más allá del estudio del periodo histórico concreto, este proyecto ha representado para la práctica totalidad del alumnado del IES Rodolfo Llopis de

\footnotetext{
${ }^{7}$ La información referida al curso de cada uno de los autores es correcta, pero todos los nombres ofrecidos son ficticios. Algunas de las citas han sido traducidas al castellano, dado que originalmente estaban escritas en catalán.
} 
Callosa d'en Sarrià el primer contacto con la historia local y la primera experiencia de trabajo con fuentes primarias de una realidad próxima.

Es importante destacar los resultados obtenidos y las valoraciones del alumnado. La concienciación para con los Derechos Humanos, el conocimiento de la historia local y la educación en la memoria democrática han cumplido con los objetivos fijados. Esto es, sostenemos que la vinculación de la historia local con los $\mathrm{DDHH}$ ha posibilitado la integración de la memoria democrática en la memoria semántica del alumnado, superando la concepción de "contenido curricular” y despertando el interés del alumnado. Nos reafirmamos en la hipótesis que motivó el inicio de este proyecto: la historia local es el instrumento más adecuado para el trabajo y la comprensión del pasado reciente. Por su capacidad de generar interés y empatía por el alumnado y por la facilidad de integrar el trabajo con fuentes primarias, la relación pasado-presente y el patrimonio material e inmaterial de nuestro entorno geográfico.

El análisis de los resultados nos permite afirmar que el trabajo sobre la historia local, como mecanismo de conocimiento del pasado y de aproximación a los valores democráticos, ha sido clave en la consecución de los objetivos. Un instrumento que nos ha permitido conducir al alumnado a debates y reflexiones que partiendo del contenido curricular de la materia, nos han permitido facilitar la construcción de aprendizajes transversales y críticos para su futuro educativo y social.

La problematización del pasado reciente de su entorno social, cultural y geográfico, nos ha permitido avanzar hacia una comprensión empática del pasado que supere el "contenido de las clases” y se conciba como un aprendizaje para la vida. Dicho de otro modo, consideramos que la historia local ha sido el instrumento fundamental e imprescindible que ha permitido ampliar la comprensión del alumnado y extendiendo su campo de reflexión, trascendiendo las lecciones teóricas y la acumulación de información para superar satisfactoriamente los requisitos académicos, para convertirse en aprendizajes transversales para su futuro.

Entendemos que la concienciación y el nivel de implicación empática del alumnado no hubiesen sido posibles mediante el estudio general de la Guerra Civil ni sus consecuencias. La aproximación a unos espacios, referencias y personajes que conciben como cercanos y propios ha sido clave para estimular sus procesos de aprendizaje significativo, desarrollar una educación que supere los límites curriculares e introducir nuevas formas de concebir e interactuar con la historia.

A su vez, se han implementado desafíos procedimentales para el alumnado, vinculados con las competencias clave de su etapa, que valoramos de forma notable: el trabajo con fuentes documentales primarias, la introducción en la historia oral, las experiencias investigadoras y el trabajo colectivo y cooperativo.

En cuanto a los aspectos a mejorar para futuros proyectos similares, se deben destacar tres. En primer lugar, la duración del mismo: entendemos que un mayor número de sesiones destinadas a cada grupo nos hubiera permitido aumentar exponencialmente los resultados, dado que los cortos plazos en los que nos hemos visto obligados a trabajar y cerrar este proyecto han determinado en gran medida las actividades y la calendarización de las mismas. En segundo lugar, y en este mismo sentido, consideramos que debe ser estudiada la posibilidad, para futuras ediciones, de implementar este proyecto durante el tercer trimestre, ya que es el espacio temporal en que la mayor parte del alumnado estudia el período referente al contexto histórico de la II República, la Guerra Civil y la Dictadura franquista. En tercer lugar, también hemos podido observar que las actividades programadas y la confección de las unidades didácticas, así como del contenido, para el primer ciclo de ESO eran excesivamente ambiciosas. La introducción de conceptos abstractos, como la memoria democrática o los derechos humanos, y el objetivo de construir un marco contextual del período histórico trabajado, han aportado un nivel de exigencia muy elevado para el alumnado. Así, somos conscientes de que, para próximas ediciones, tenemos que trabajar en una mayor adaptación de los contenidos propuestos y en nuevos mecanismos y estrategias de trabajo. 
Por último, nos gustaría poner de relieve las ventajas observadas durante la realización de este proyecto e incidir en nuestra convicción de que hay que seguir trabajando, poniendo en valor y difundiendo la memoria democrática en los institutos de educación secundaria valencianos, sin olvidar que es una tarea pendiente para el conjunto de la sociedad y se han de construir espacios de aprendizaje y reflexión que conecten los centros escolares con el conjunto de la sociedad.

\section{Referencias}

Bel Martínez, J.C. y Colomer Rubio, J.C. (2017). Guerra Civil y franquismo en los libros de texto actuales de Educación Primaria: análisis de contenido y orientación didáctica en el marco de la LOMCE. Cabás-Revista digital sobre el PHE, 17, 1-17.

Chartier, R. (2005). El presente pasado. Escritura de la historia, historia de lo escrito. México: Universidad Iberoamericana.

Colomer, J.C.; Esteve, J. e Ibáñez, M. (coords.) (2015). Ayer y hoy. Debates, historiografía y didáctica de la historia. Valencia: PUV.

Cuesta, R. (2011a). Historia con memoria y didáctica crítica. Con-ciencia social, 15, 15-30.

Cuesta, R. (2011b). Memoria, historia y educación: genealogía de una singular alianza. En C. Lomas (coord.), Lecciones contra el olvido. Memoria de la educación y educación de la memoria (pp. 163-195). Barcelona: Octaedro.

Díez Gutiérrez, E. J. (2001). Análisis de los textos escolares de historia. Estudio de caso sobre la posguerra civil española. Revista Historia de la Educación Latinoamericana, 16, 87-118.

Díez Gutiérrez, E. J. (2014). La memoria histórica en los libros de texto escolares. Revista Complutense de Educación, 25(2), 393-409. DOI: 10.5209/rev_RCED.2014.v25.n2.41613.

Fontana, J. (2015). Enseñar historia con una guerra civil de por medio. En A. Carrillo-Linares (coord.), La Historia aprendida y enseñada: reflexiones polifónicas (131-142). Sevilla: Editorial Universidad de Sevilla.

Fraser, R. (2007). Recuérdalo tú y recuérdalo a otros. Historia oral de la guerra civil española. Barcelona: Crítica.

Fuertes, C. (2018). La dictadura franquista en los manuales escolares recientes: una revisión crítica. Revista Historia Autónoma, 12, 279-297. DOI: 10.15366/rha2018.12.015.

Galiana i Cano, V. (2015). Un entre tants. Història de vida de Javier Tasa Sanchis, afusellat pel franquisme. Saó, 409, 99-31.

Galiana i Cano, V. (2016). Travessar la (des)memòria: una aproximació a la repressió franquista de postguerra a Callosa d'en Sarrià. Sarrià, Revista d'investigació i assaig de la Marina Baixa, $12,153-164$.

Galiana i Cano, V. (2017). Dolor, trauma, fam i oblit. Les quatre cares del primer franquisme a Callosa d'en Sarrià. En V. Galiana i Cano y E. Marín Moreno (coords.), Històries del nostre poble. Un passeig per la Callosa d'en Sarrià del s.XX (pp. 101-128). Callosa d'en Sarrià: Ajuntament de Callosa d'en Sarrià.

Gómez Bravo, G. y Marco, J. (2001). La obra del miedo: violencia y sociedad en la España franquista (1936-1950). Barcelona: Ediciones Península.

González Cortés, J. R. (2014). Los pasados recientes en conflicto y sus implicaciones didácticas: Guerra civil y Transición. Con-ciencia social: anuario de didáctica de la geografía, la historia y las ciencias sociales, 18, 157-164.

Grupo Ínsula Barataria (1994). Criterios y pautas para la elaboración de materiales para la enseñanza: el modelo didáctico. En Grupo Ínsula Barataria (Coord), Enseñar y aprender Ciencias Sociales. Madrid: Mare Nostrum.

Iniesta González, M. (2011). Instrumentos para una política de la memoria. El memorial democrático de Cataluña. En El lugar de la memoria. Seminario sobre un centro de memoria 
en el País Vasco, Conferencia pronunciada en Bilbao, en noviembre de 2011. Recuperado de http://www.bideo.info/buesa/imagenes/seminario_iniesta.pdf [20 de noviembre de 2017]

Maestro, P. (2002). El modelo de las historias generales y la enseñanza de la historia. Didáctica de las Ciencias Experimentales y sociales, 16, 3-33.

Míguez, A. (2014). La genealogía genocida del franquismo. Violencia, memoria e impunidad. Madrid: Abada Editores.

Molpeceres, A. (2011). Conflictos: la memoria de los alumnos. De la Guerra Civil a la transición. Iber, 69, 21-28.

Montoya, Ma . M. (2008). Enseñar: una experiencia amorosa. Madrid: Sabina Editorial.

Morgade Valcárcel, I. (2017). "Tras las huellas del maestro”: Una propuesta didáctica para el tratamiento de la represión de la memoria en el aula”. Didáctica de las Ciencias Experimentales y sociales, 32, 3-23, DOI: 10.7203/DCES.32.8207.

Núñez Díaz-Balart, M. (2009). La Gran Represión. Los años de plomo del franquismo. Barcelona: Flor de Viento.

Prades, S. (2016). Las fuentes orales en la Educación Secundaria: motivación y aprendizaje de la Historia. Didáctica de las ciencias experimentales y sociales, 30, 85-101. DOI: 10.7203/DCES.30.4478.

Proyecto Gea-Clío y Souto, X. M. (2001). La didàctica de la geografia i la historia en un món globalitzat i divers. València: Eines d'innovació educativa, L’Ullal.

Rüsen, J. (2007). Memory, history and the quest for the future. En L. Cajani (Ed.), History, Identities and Citizenship (pp. 13-34). Stoke on Trent/Sterling: Trentham Books.

Valls, R. (2007). La guerra civil española y la dictadura franquista: las dificultades del tratamiento escolar de un tema potencialmente conflictivo. Enseñanza de las ciencias sociales, 6, 61-73.

\section{CÓMO CITAR ESTE ARTÍCULO}

Galiana i Cano, V. (2018). La memoria democrática en las aulas de secundaria y bachillerato: balance de una experiencia didáctica. Didáctica de las ciencias experimentales y sociales, 34, 318. DOI: $10.7203 /$ DCES.34.12048. 